\title{
SYNTHESIS AND CHARACTERIZATION OF SOME NOVEL STILBENE DERIVATIVES DERIVED FROM SUBSTITUTED (PHENYL ACETIC ACID, BENZALDEHYDE, AMINES ) TRIETHYL AMINE AND THIONYL CHLORIDE.
}

\author{
Paresh S. More* and Santosh G. Singh \\ *Department of Chemistry, KET'S V.G Vaze College, Mulund, Mumbai-400081,Maharashtra, India. \\ Email: paresh.m34@gmail.com
}

\begin{abstract}
:
Stilbene derivatives are widely distributed in the nature and they possess various bioactivities that includes antimicrobial, antifungal, antioxidant, hepato protective, anti-HIV, cytotoxic, antiinflammatory and antiplatelet. We have synthesized novel derivatives of stilbenes by reacting various substituted phenyl acetic acid with aldehydes in presence of acetic anhydride and triethyl amine. These derivatives were characterised by various spectral techniques and were evaluated for their antimicrobial activities.
\end{abstract}

Keywords: Stilbenes, phenyl acetic acid, Antimicrobial activity.

\section{INTRODUCTION}

Synthesis of functionalized stilbene have attracted immense attention over the past decades and have been reported in several research papers and reviews. ${ }^{1-4}$

Stilbenes are biologically active secondary metabolites found in numerous families of plants and is derived from the greek word 'stilbos', which means shining. Chemically stilbenes are derivatives of 1, 2-diphenyl ethane. Stilbene itself does not occur in nature but hydroxylated and methylated stilbenes are found in medicinal plants. Stilbene derivatives such as diethylstilbestrol(DES), euvestin, 4,4' diaminostilbene and pinosylvin, have a variety of biological action, including hormonal, hypo cholesterolemic, sympathomimetic, antifungal, anti allergic, antibacterial, anti malarial and anticancer activities. ${ }^{5-8}$. DES is the mostfamous stilbene derivative, which was used medically for prostate and breast cancerand to preventthreatened abortions ${ }^{9-11}$.

Resveratrol (4,3',5'- trihydroxy stilbene) which is found in grapes, peanuts, pine- apple and also grape products such as wine, exerts potent anti oxidant and anti inflammatory activities $^{12-14}$.

The development of methods for their effective construction has attracted considerable attraction in organic synthesis. The synthesisof stilbene derivativeshas been an important part and is aimed at modifying the action of drugs particularly to reduce the side-effect along with increasing the drug action. Thus in agreement with their role as anti-oxidant ${ }^{15-16}$, antiinflammatory ${ }^{17-18}$, anti-cancer ${ }^{19}$. Our interest in the field of substituted stilbene, total synthesis of stilbene and their several analogues. In the light of the above discussion it was 
thought important to undertake the synthesis of some novel stilbene derivatives and to characterize them by using various spectral techniques such as ${ }^{1} \mathrm{H}-\mathrm{NMR}$, IR and elemental analysis.

\section{EXPERIMENTAL PROCEDURE}

${ }^{1} \mathrm{H}$ NMR spectra were recorded on a Brukner Act $300(300 \mathrm{Mz})$ spectrophoto-meter and .Elemental analyses were carried out at department of chemistry University Of Mumbai. Infrared spectra were recorded on Perkin Elmer FTIR-4200 spectrometer at V.G.Vaze college. All the melting points are uncorrected. Temperature was recorded in ${ }^{0} \mathrm{C}$.

Procedure for the preparation of some novel stilbene derivatives from substituted benzaldehyde, substituted phenyl acetic acid and triethyl amine.

\section{Preparation of carboxylic acid.}

A mixture of phenyl acetic acid, substituted benzaldehyde (equimolar) was refluxed along with triethyl amine for $24 \mathrm{hrs}$ and the reaction mixture was break in sodium carbonate solution and left for $24 \mathrm{hrs}$. The mixture was extracted with ether. The aqueous solution was acidified with dilute HCL and the ppt.wasfiltered and dried in vaccum and used without further purification.

\section{Preparation of Substituted stilbene derivatives (Enamide) from carboxylic acid.}

A mixture of carboxylic acid ,thionyl chloride and benzene was refluxed for 6 hrs. Further it was treated with aqueous methyl amine solution. The precipitated product was filtered washed with very dilute $\mathrm{NaOH}$ solution and dried and used without further purification.

\section{RESULT AND DISCUSSION.}

Synthesized compounds PM-01 to PM-04, their theoretical and practical data of elemental analysis are in very good agreement as depicted in the table1, which confirms formation of carboxylic acid and its amide derivatives.

IR Spectral data(cm-1) and ${ }^{1} \mathrm{H}$ NMR Spectral data of the substituted stilbene and derivatives of stilbene is shown in the table2.

Table 1.Physical and Analytical data of the substituted stilbene and derivatives of stilbene.

\begin{tabular}{|c|c|c|c|c|c|c|c|c|c|}
\hline Compound & $\begin{array}{l}\text { Molecular } \\
\text { fomula }\end{array}$ & $\begin{array}{c}\text { Molecular } \\
\text { weight }\end{array}$ & $\begin{array}{c}\% \\
\text { yield }\end{array}$ & $\begin{array}{c}\text { Melting } \\
\text { point }\end{array}$ & Colour & Carbon & Hydrogen & Nitrogen & Chlorine \\
\hline PM-01 & $\mathrm{C}_{15} \mathrm{H}_{11} \mathrm{O}_{2} \mathrm{Cl}$ & 258 & 70 & 170 & White & $\begin{array}{c}69.49 \\
(69.00)\end{array}$ & $\begin{array}{c}4.24 \\
(3.95)\end{array}$ & - & $\begin{array}{c}13.70 \\
(13.25)\end{array}$ \\
\hline PM-02 & $\mathrm{C}_{15} \mathrm{H}_{13} \mathrm{ON}_{2} \mathrm{Cl}$ & 272 & 70 & 95 & Yellow & $\begin{array}{c}66.17 \\
(65.80)\end{array}$ & $\begin{array}{c}4.77 \\
(4.55)\end{array}$ & $\begin{array}{c}10.29 \\
(10.10)\end{array}$ & $\begin{array}{c}13.05 \\
(12.85)\end{array}$ \\
\hline PM-03 & $\mathrm{C}_{16} \mathrm{H}_{14} \mathrm{NOCl}$ & 271 & 63 & 112 & White & $\begin{array}{c}70.84 \\
(70.24)\end{array}$ & $\begin{array}{c}5.16 \\
(4.95)\end{array}$ & $\begin{array}{c}5.16 \\
(4.92)\end{array}$ & $\begin{array}{c}13.09 \\
(12.64)\end{array}$ \\
\hline PM-04 & $\mathrm{C}_{17} \mathrm{H}_{16} \mathrm{ONCl}$ & 258 & 68 & 290 & White & $\begin{array}{c}79.06 \\
(78.45)\end{array}$ & $\begin{array}{c}6.20 \\
(5.84)\end{array}$ & $\begin{array}{c}5.42 \\
(5.15)\end{array}$ & $\begin{array}{c}13.75 \\
(13.23)\end{array}$ \\
\hline
\end{tabular}


Table 2 .IR Spectral data $(\mathrm{cm}-1)$ and ${ }^{1} \mathrm{H}$ NMR Spectral data of the substituted stilbene and derivatives of stilbene.

\begin{tabular}{|c|c|c|c|c|c|c|c|c|c|c|c|}
\hline \multirow[t]{2}{*}{ COMPOUND } & \multicolumn{6}{|c|}{ IR SPECTRAL DATA $\left(\mathrm{cm}^{-1}\right)$} & \multicolumn{5}{|c|}{ ${ }^{1}$ H NMR Chemical Shift ( $\delta$ ppm) } \\
\hline & $\begin{array}{l}v_{(\mathrm{C}-\mathrm{H})} \\
\text { aromatic }\end{array}$ & $\begin{array}{l}v_{\text {(C-H) }} \\
\text { aliphatic }\end{array}$ & $v_{(\mathrm{c}-\mathrm{o})}$ & $v_{(\mathrm{C}=\mathrm{C})}$ & $v_{(\mathrm{C}-\mathrm{C})}$ & $v_{(\mathrm{C}-\mathrm{NH})}$ & $\begin{array}{c}1 \mathrm{H}- \\
\mathrm{COOH}\end{array}$ & $\begin{array}{l}1 \mathrm{H}- \\
\mathrm{CH}\end{array}$ & $\begin{array}{c}\text { 9HAr- } \\
\mathrm{H}\end{array}$ & ${ }^{1} \mathrm{H}-\mathrm{NH}$ & $\begin{array}{l}2 \mathrm{H}- \\
\mathrm{NH}_{2}\end{array}$ \\
\hline $\mathrm{C}_{15} \mathrm{H}_{11} \mathrm{O}_{2} \mathrm{Cl}(\mathrm{PM} 01)$ & 3035 & 2925 & 1680 & 1620 & 550 & - & 10.25 & 7.38 & $\begin{array}{l}7.31- \\
6.54\end{array}$ & - & - \\
\hline $\mathrm{C}_{15} \mathrm{H}_{13} \mathrm{ON}_{2} \mathrm{Cl}(\mathrm{PM} 02)$ & 3022 & 2924 & 1618 & 1591 & 548 & $\begin{array}{l}3344- \\
3378\end{array}$ & & 8.92 & $\begin{array}{l}8.05- \\
6.93\end{array}$ & 12.95 & $\begin{array}{l}5.38- \\
3.36\end{array}$ \\
\hline $\mathrm{C}_{16} \mathrm{H}_{14} \mathrm{NOCl}(\mathrm{PM} 03)$ & 3095 & 2825 & 1605 & 1600 & 545 & 3350 & & 8.90 & $\begin{array}{l}7.76- \\
6.91\end{array}$ & 12.89 & - \\
\hline $\mathrm{C}_{17} \mathrm{H}_{16} \mathrm{ONCl}(\mathrm{PM} 04)$ & 3040 & 2850 & 1700 & 1595 & 560 & 3300 & & 8.25 & $\begin{array}{l}7.25- \\
6.85\end{array}$ & 13.50 & - \\
\hline
\end{tabular}

\subsection{IR Spectra}

Infrared spectra of the acid obtained from substituted phenyl aceic acid (PM01) and its amide derivatives(PM02-PM04) were compared. The spectra of derivatives showstwo sharp bands in the range of $3350-3378 \mathrm{~cm}^{-1}$ which is assigned for NH- Stretching. This band was absent in PM-01 as depicted in the representative IR spectra of PM-01where as PM-02 shows sharp band. The aromatic C-H stretching at $3022-3095 \mathrm{~cm}^{-1}$,AliphaticC-H stretching at 2825-2925 $\mathrm{cm}^{-1}$. CO Stretching at $1605-1700 \mathrm{~cm}^{-1}, \mathrm{C}=\mathrm{C}$ stretching at $1591-1620 \mathrm{~cm}^{-1}, \mathrm{C}-\mathrm{C}$ stretching at $540-560 \mathrm{~cm}^{-1}$ were assigned for PM01-PM04 ${ }^{20-21}$.

\section{2. ${ }^{1} \mathrm{H}$ NMR Spectra}

The ${ }^{1} \mathrm{H}$ NMR Spectra of the PM01 to PM04 were recorded in DMSO solvent and the assignement are detailed in the table. The signal appeard in the region of $10.25 \mathrm{ppm}$ confirms presence of $\mathrm{COOH}$ as shown in the representative spectra of PM01. Absence of this signal in all other spectra and new peaks in the region of 12.95 to $13.50 \mathrm{ppm}$ confirms presence of NH in PM02 to PM04. In PM02 new peak in the range of 5.38 to $3.36 \mathrm{ppm}$ indicates $-\mathrm{NH}_{2}$. The multiplates in the rangeof 6.50 to $7.70 \mathrm{ppm}$ were assigned to aromatic proton $20-21$ 


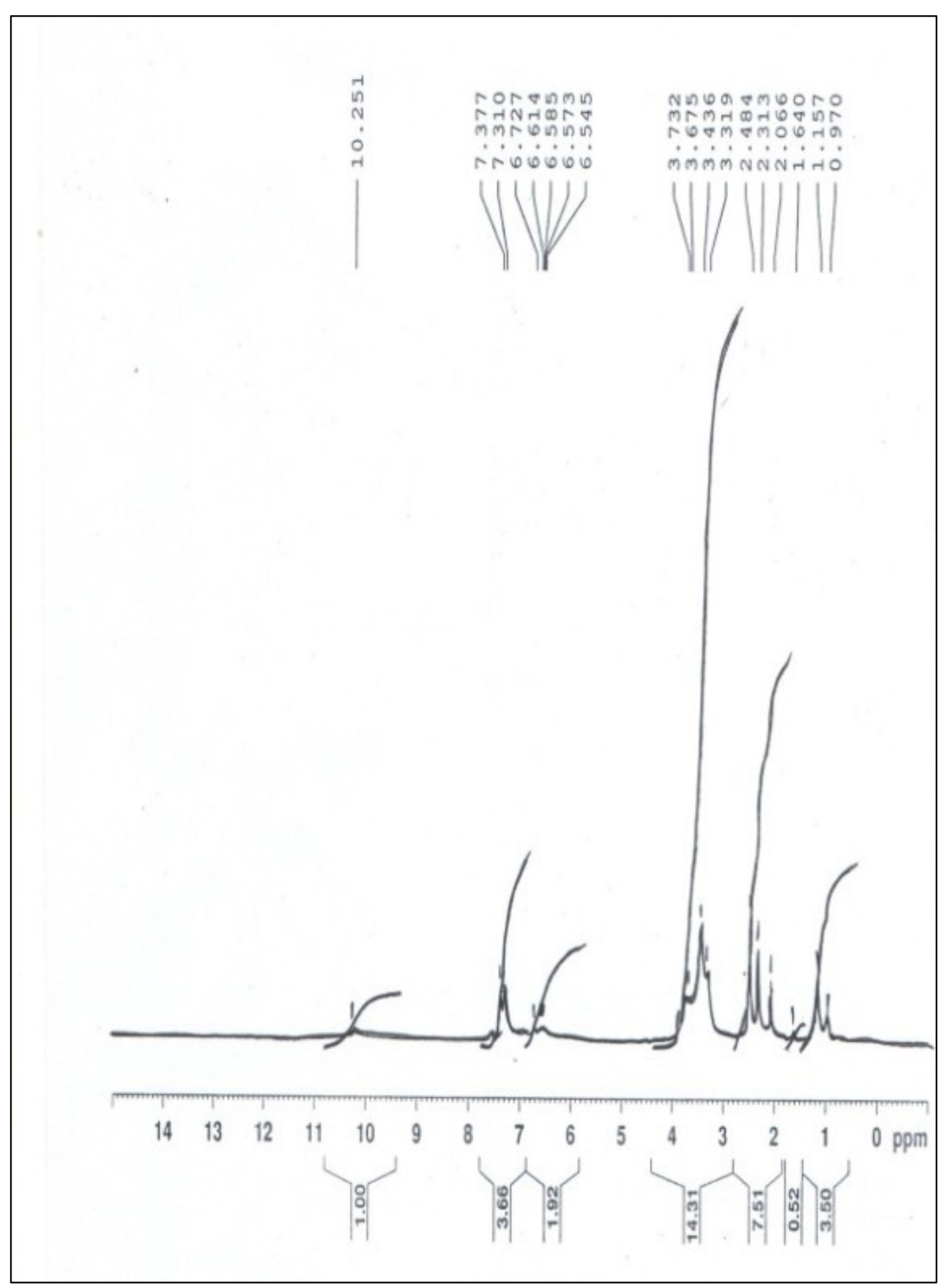

Fig.No. (1) 


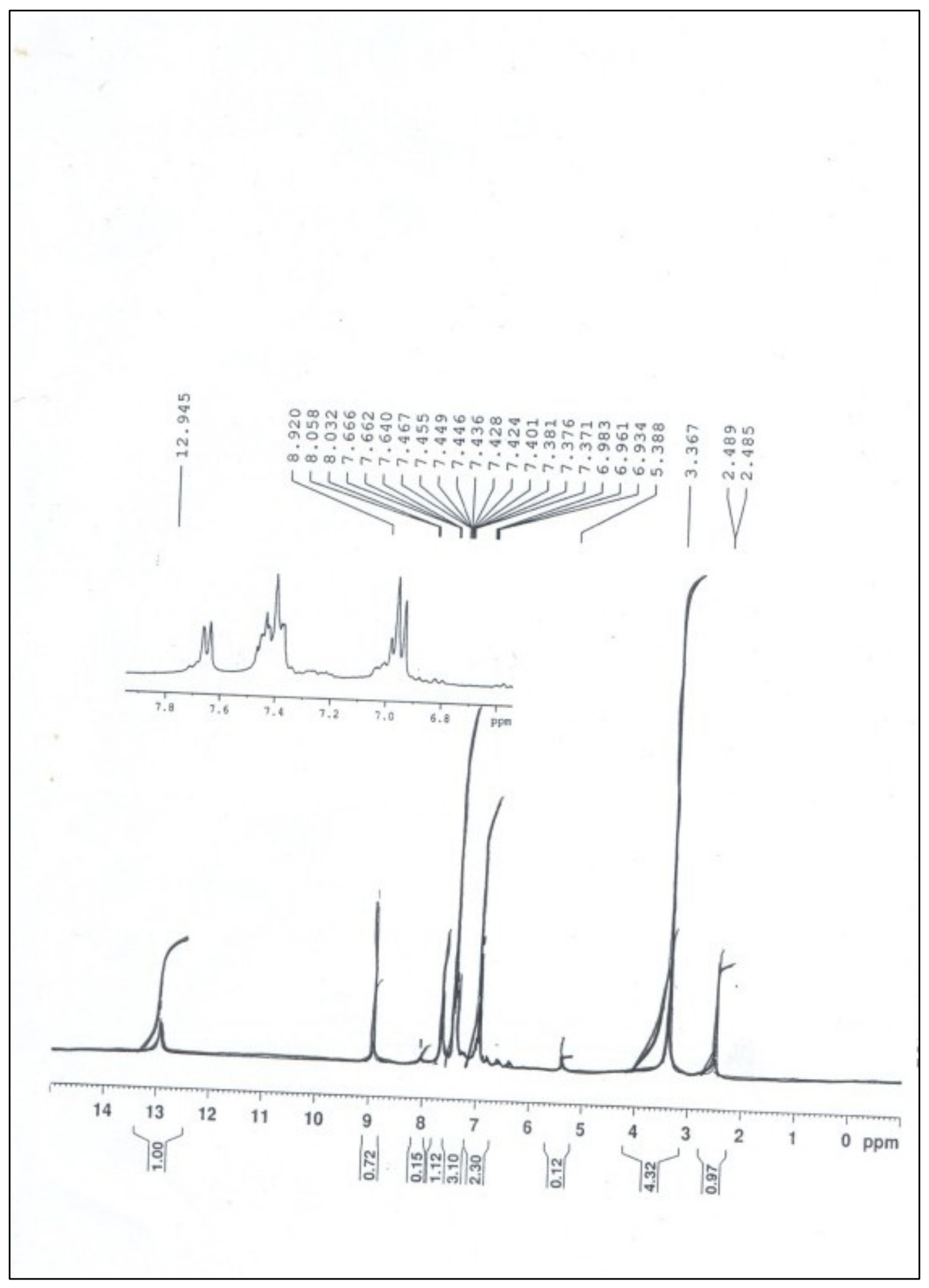

Fig.No.(2)

Fig No. (1) \& (2) : ${ }^{1}$ H-NMR Spectra of the compound PM-01 \& PM-02 


\subsection{Antimicrobial activities:}

Antimicrobial activities for all synthesized compounds were carried out by agar diffusion method and the average radius of the zone of inhibition was recovered. Among the other derivatives screened, the observations were made and compared with standard Norfloxacin $(100 \mu \mathrm{g} / \mathrm{ml})$ as shown in Table 1 .

All the synthesized derivatives showed antibacterial activity against both gram positive and gram negative bacteria at a concentration of $100 \mu \mathrm{g} / \mathrm{ml}$. Best results in terms of antibacterial activity was shown by compounds PM01, PM03, PM04 where as moderate results is shown by PM02 .

Table 3 : Antibacterial activity of some substituted stilbene derivatives

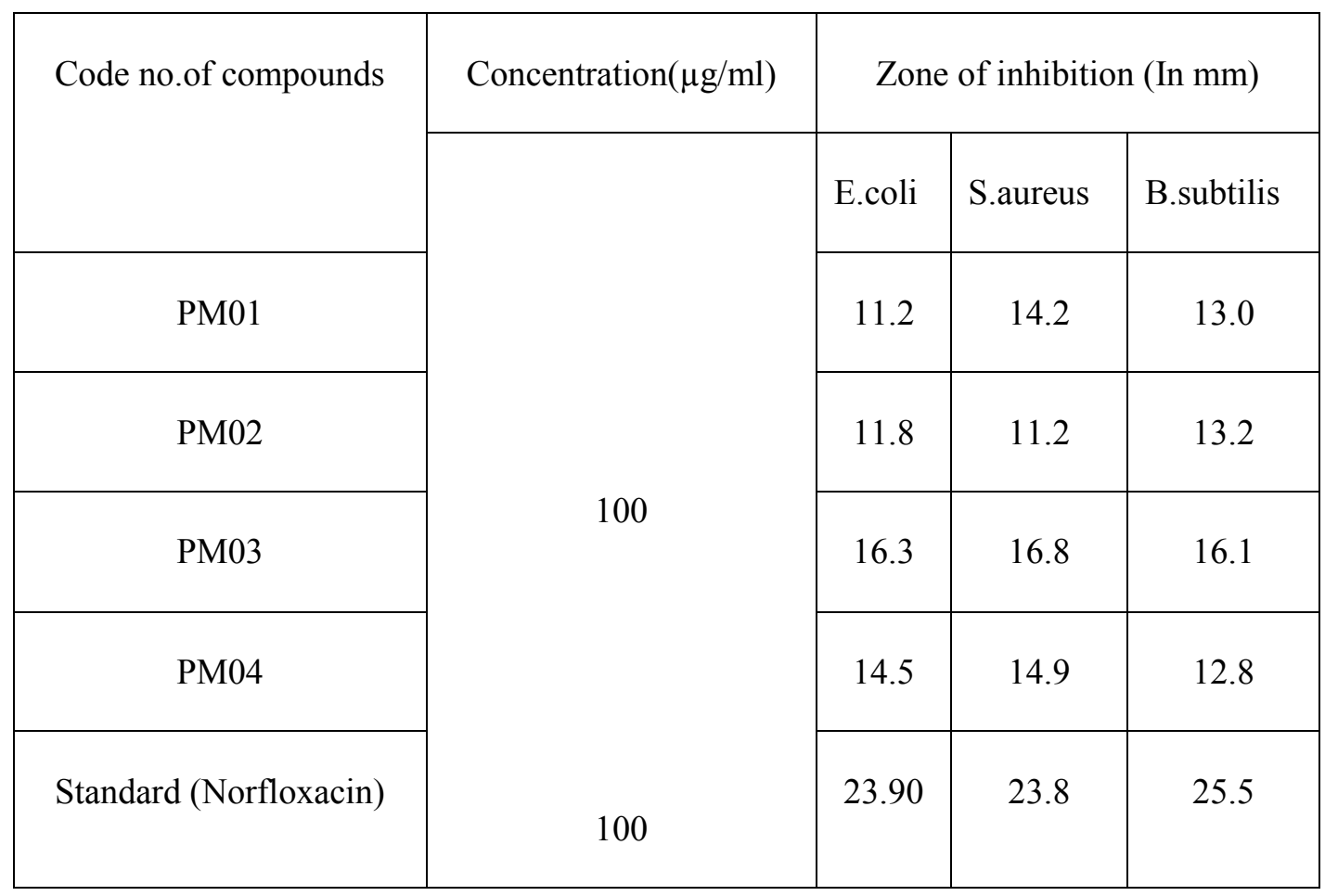

\section{CONCLUSION:}

In conclusion, it is for the first time that a very simple methodology has been employed for the synthesis of novel stilbene derivatives. All the structures are well supported by ${ }^{1} \mathrm{H} N M R$, IR and Elemental analysis. On the basis of above studies we are proposing following structure. 


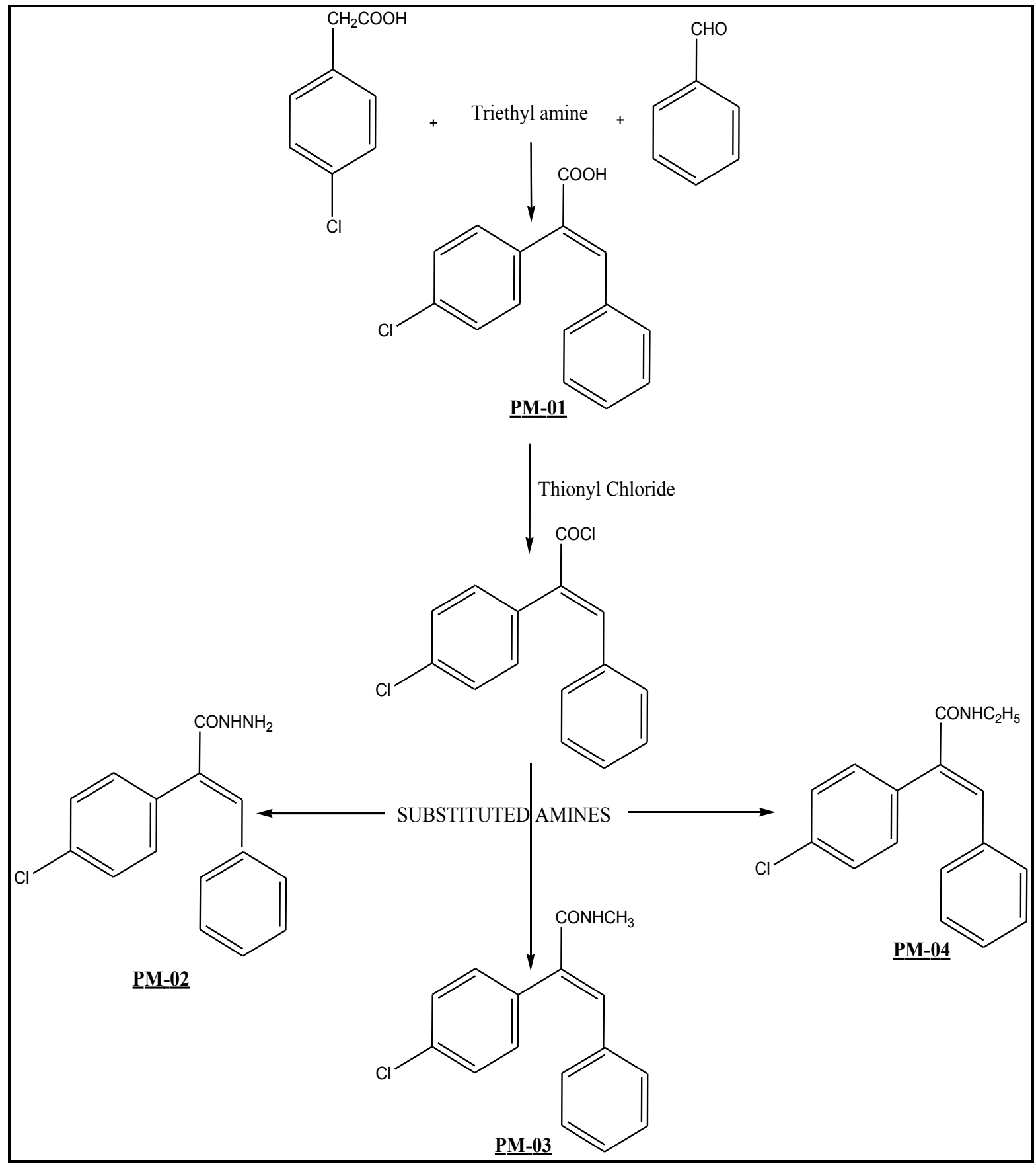

Structures of stilbene derivatives . 

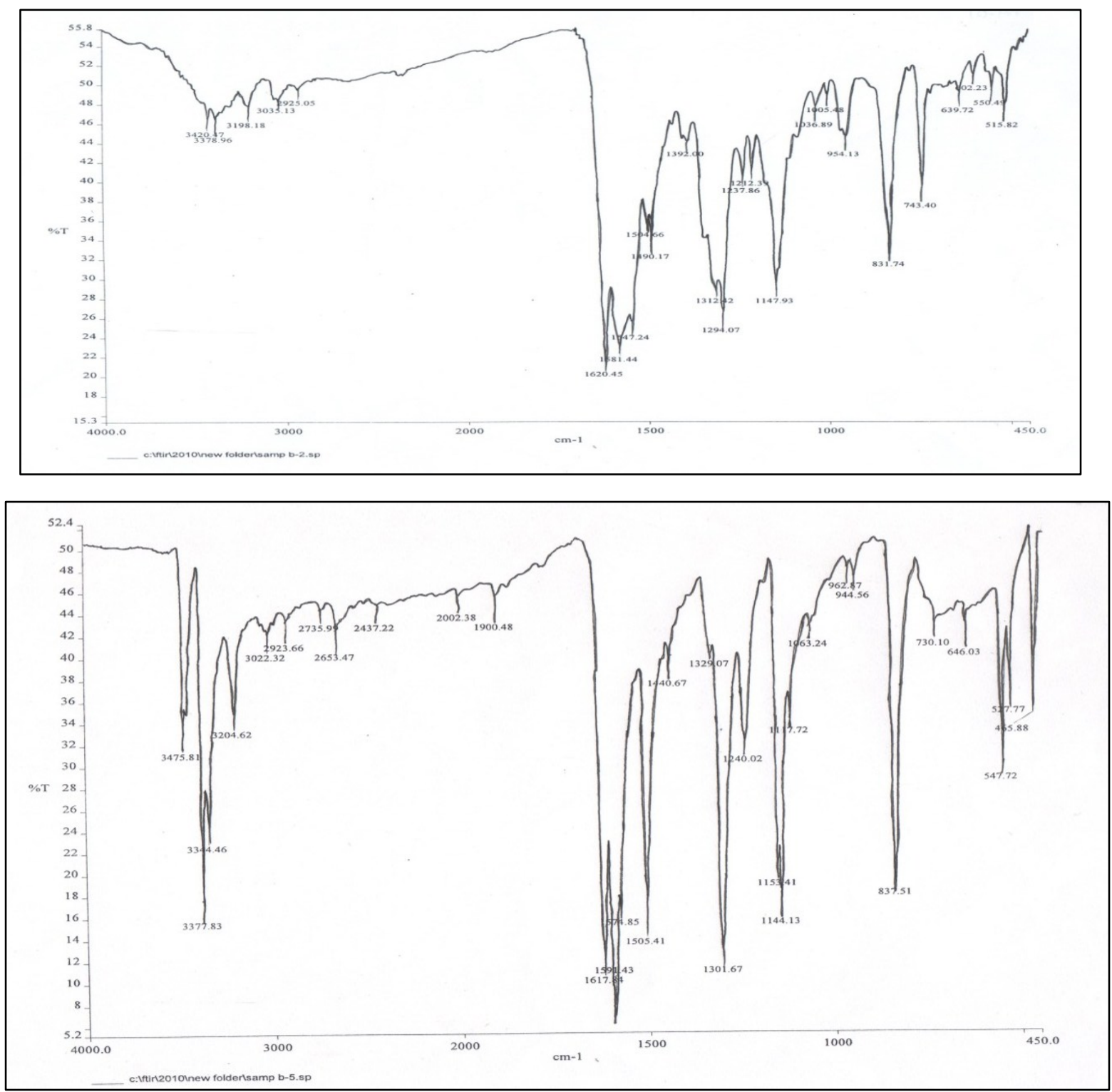

Fig. No. (4) : IR Spectra of the compound PM-02

\section{Acknowledgement:}

Authors are very thankful to the Management of V.G.Vaze College for support and encouragement. Also thankful to the Principal Dr. B.B. Sharma and HOD of Chemistry Dr. (Ms.) Vandana Panse for the laboratory facilities. 


\section{References:}

[1] K.Xiao .H.J. , Zhong.L., J .Xuan , J. Zhang.X., M.X.U and D.L. Bai. Stilbenes and bioactives Vol.34 : Bioactive Natural Products (Part N ), PP.453-646 , Elsevier B.V., Amsterdam.

[2] K.Ferre . Filmon .L. Delaude .A. Demonceau and A.F. Noels .Coordination chemistry.Rev. 2004.248.2323-2336

[3] K.B. Becker . Synthesis .1983.341-368

[4]G.Likhtenshtein . stillbenes, application in chemistry Life sciences and materials sciences, PP.1-25. Wiley-VCH Weinheim . 2010

[5] Grundy, J. (1957) Artificial estrogens , Chem. Rev., 57, 281-356

[6] Hughes .g , M.K. Moore , P.F. and Stebbins , R.B. (1964) some hypocholesteremic 2,3diphenyl-acrylonitriles.

[7] Ali .H.A, Kondo.K, and Tsuda .Y. (1992)

[8] Matsuda .H, Tomohimo .N, Hiraba . K , Harima S , K.O.S . Matuso ,k., Yoshikawa .M. and kubo , M (2001). Study on anti-oketsu activity of rhubarb II .Antiallergic effects of stilbene compounds from RheiundulatiRhizomma( dried rhizome of Rheum Undulatum cultivated in Korea ) Biol . Pharm .Bull., 24 , 264-267.

[9] Metzier , M. (1984) Biochemical toxicology of diethyl stilbestrol .Rev. Biochem . Toxicol., 6, 191-220

[10] Smith .O.W. and Brookline , M.(1948) Diethylstllbestrol in the prevention and treatment of complication of pregnancy .Am.J.obstet .Gynecol .56, 821-825

[11] Constant ,.J (1997) Alcohol, ischemic heart disease and French paradox .Coron . Artery Dis., 8, , 645-649

[12] M Jang., L. Cai., Udeani 40,K.V.Slowirg , C.F.Thomas , C.W. Beecher ,H.H. Fong, 1997, Science; 275:218-220.

[13] P. Signorelli, R. Ghidoni , 2005, .J. Nutr. Biochem, 16:446-49.

[14] J.H. Hart , 1991, Annu.Rev.phytopathol,19:437-58.

[15] M. Robert, D. Pizzirani, 2004, J .Org. Chem;2004;69:7101-07

[16] M. Agens, D. Pizzirani, 2004, J. Org .Chem; 69:7101-7107.

[17] A. R. Martin, I. Villegas, M. Sanchez-Hidalgo, C. A. Br. De la lastro, 2006, J.Pharmacol., 147(8):873-885.

[18] L.E.Donelly, R. Newton, G E Kennedy, Fenwick P S Ito K, EK Richard and PJ Am. Barmes, 2004, J. Physiol Lung Cell Mol Physiol., 287,774-783. 
[19] G.A.Potter, L.H. Patterson, Wanoghot, P.J. Perry, P.C. Butler, 2002, British Journal of Cancer, 86 774-778.

[20] B.H. Mehta and P.S. More , Asian Journal Of Chemistry , vol.19 , No.5 (2007) 47194726.

[21] B.H.Mehta and P.S.More , Asian Journal Of Chemistry , Vol.19 , No.5 (2007) , 35813587.

( Received 22 November 2014; accepted 11 December 2014 ) 